\title{
Prospective Study to find out whether Continuous Curvilinear Capsulorrhexis is mandatory to achieve a Good Result in Phacoemulsification
}

\author{
Author \\ Dr. K.M Suresh, MBBS, MS (OPH) \\ Medical Director Vidya Eye Hospital, \# 47/E ,15 ${ }^{\text {th }}$ Main, MC Road,Vijayanagar, Bangalore 560040 \\ Email: drkmsuresh@hotmail.com,PH.23389854, Mob: 9845378853 \\ Website: www.vidyaeyehospital.com
}

\begin{abstract}
Aim of this study is to find out whether it is mandatory to do Curvilinear continuous capsulorhexis(CCC) to achieve a good result in phacoemulsification. Materials and methods consisted of a prospective, randomised study of 150 patients, out of which 75 patients with cataract who were operated by CCC technique before phacoemulsification with intraocular lens implantation(IOL), categorized into group 1 and another group2, where in, in another 75 cataract affected patients, can-opener technique of anterior capsulotomy was done before phacoemulsification with lens implantation. The results of both the groups were tabulated and compared. The results obtained, showed that there was no significant, clinical and statistical differences between the values of two groups. The study concluded that even though it is appreciable to do CCC before phacoemulsification, it is not mandatory to do this method, prior to phacoemulsification, as can-opener technique of anterior capsulotomy done, before phacoemulsification with intraocular lens implantation (IOL), is as effective as the former
\end{abstract}

\section{Relevance of the study}

Many young surgeons are rather enthusiastic to do phacoemulsification and rejoice its success, in their juvenile surgical hands. They in fact get frustrated and disheartened, if they are not able to achieve a good continuous, curvilinear capsulorhexis, a feeling which in fact dampens them to proceed further to complete, a good phacoemulsification procedure. This study compares two groups of patients, one who underwent text book defined $\mathrm{CCC}$, and the other group who underwent anterior capsulotomy by can-opener technique. The results of these two are compared to find out, whether, it is mandatory and stringent to perform the text-book explained version of $\mathrm{CCC}$ to expect a good overall result in Phacoemulsification with IOL implantation.

\section{Aim}

Aim of this study was to find out, whether it is mandatory or stringent, to perform, and complete CCC for expecting a good end result in phacoemulsification with IOL implantation 


\section{Materials and Methods}

Total of 150 cases were selected for the study. The cases, which had only cataract and had no other associated ocular diseases, were chosen for the study. The cases were from Jan 2009 to Dec 2015. In group 1 which included 75 patients, a typical well defined CCC was performed before phacoemulsification with IOL implantation. Group 2 included total of 75 patients who underwent canopener technique before phacoemulsification with IOL implantation. All the surgeries were done by the same surgeon in the same centre. All 150 surgeries were done under topical anaesthesia

$3.2 \mathrm{~mm}$ clear corneal incision was put at 12 'o clock meridian, methyl-cellulose was used as a viscoelastic substance and cystitome was used to perform both CCC and can-Opener technique.

For Group1, CCC was done with a 2-bend cystitome made out of 1 inch 26 gauge needle, Tryphan blue was used to enhance the visibility of the anterior capsule. The initial puncture on the anterior surface of the anterior capsule was done at 9 o'clock meridian at a point on the imaginary circumference of CCC to be achieved, later two arcs along the desired circumference of CCC are made, one running inferiorly and another running superiorly, the meeting point of these two arcs are chosen according to the manoeuvrability that is permissible in a particular case. The circular flap thus created is aspirated out of the anterior chamber. For group2, the can-opener technique was done by a 2-bend cystitome made out of 1 inch 26 gauge needle, Tryphan blue was used to enhance the visibility of the anterior capsule. Perforations of anterior capsule were made at $6 \mathrm{~mm}$ circumference from the centre of the lens, these perforations were joined to remove a circular anterior capsular flap.

Later steps of the procedure like hydro-delineation, hydro-dissection, phaco-fragmentation, phacoemulsification, irrigation, aspiration, and foldable intraocular lens implantation were done in similar manner for both the groups of patients

The parameters used for assessing the results were, extension of capsulotomy to equator of the lens, vitreous loss, mobility of the nucleus in the capsular bag, corneal clarity, lens tilt astigmatism and postoperative vision on $6^{\text {th }}$ week of postoperative day.

Vitreous loss and posterior capsular tear were managed by anterior vitrectomy and implantation of the posterior chamber lens, on the remnants of the anterior and posterior capsule, or by anterior vitrectomy and primary anterior chamber lens implantation.

\section{Results}

In first group (Group1) of patients, vision better than 6/18 unaided was achieved in 70 cases (93.33\%). Extension of capsulorrhexis to the periphery and hence vitreous loss were observed in 6 cases $(8 \%)$. The reason for extension in two cases was extremely thin capsule. In four cases it was due to fibrosis and adherence of the capsule to the underlying cortex. In 3 cases (4\%) Posterior chamber intraocular lens implantation were done on the remnants of the anterior and posterior capsules while in remaining 3 cases (4\%) primary anterior chamber intraocular lens implantation procedures were performed. Good mobility of the nucleus was achieved in 71 cases $(94.66 \%)$, lens tilt astigmatism was seen in 3cases $(4 \%)$.

In second group (Group2) of patients, 69 cases (92\%) achieved, unaided 6/18 vision. Peripheral extension of anterior capsulotomy occurred in 7 cases $(9.33 \%)$. In 3 cases $(4 \%)$ it occurred during Can-Opener technique, while in 4 cases $(5.33 \%)$ it occurred during phacoemulsification procedure. In 4 cases $(5.33 \%)$ posterior chamber implantation was done on the remnants of the anterior and posterior capsule while in 3 cases $(4 \%)$ primary anterior chamber intraocular lens implantation was done. Mobility of the nucleus was very well achieved in 74 cases $(98.66 \%)$ in this group. Mobility was so good that in 25 cases $(33.33 \%)$ we were able to see the posterior surface of nucleus tumbling anteriorly, after the $2 / 3^{\text {rd }}$ trenching of the nucleus was done on the anterior surface. This phenomenon helped us to complete trenching easily and there by facilitating division of nucleus. Prevention of nucleus sinkage (nucleus drop) in 3 cases was done by passing 18 
gauge needle through pars -plana and elevating it slightly, meantime taking care to protect the cornea.

\section{Table1}

\begin{tabular}{|l|l|l|l|l|}
\hline Parameters & Group 1 & Group2 & MD & SD \\
\hline $\begin{array}{l}\text { Vision>6/18 } \\
\text { (better than) }\end{array}$ & $\begin{array}{l}70 \\
(93.33 \%)\end{array}$ & $\begin{array}{l}69 \\
(92 \%)\end{array}$ & 0.5 & 0.5 \\
\hline Vitreous loss & $\begin{array}{l}6 \\
(8 \%)\end{array}$ & $\begin{array}{l}7 \\
(9.33 \%)\end{array}$ & 0.5 & 0.5 \\
\hline $\begin{array}{l}\text { Mobility of } \\
\text { Nucleus }\end{array}$ & $\begin{array}{l}71 \\
(94.66 \%)\end{array}$ & $\begin{array}{l}74 \\
(98.66 \%)\end{array}$ & 1.5 & 1.5 \\
\hline $\begin{array}{l}\text { Corneal } \\
\text { clarity }\end{array}$ & $\begin{array}{l}75 \\
(100 \%)\end{array}$ & $\begin{array}{l}75 \\
(100 \%)\end{array}$ & 0 & 0 \\
\hline $\begin{array}{l}\text { Lens tilt } \\
\text { astigmatism }\end{array}$ & $\begin{array}{l}3 \\
(4 \%)\end{array}$ & $(5.33 \%)$ & 0.5 & 0.5 \\
\hline
\end{tabular}

In both the groups corneal clarity was achieved in all 75 cases $(100 \%)$ at the end of $6^{\text {th }}$ concluding week.

\section{Discussion}

From the results obtained in our study, we observed that in $93.33 \%$ in Group1 and 92\% in Group2 had unaided vision better than 6/18. These data are noticeably closer to each other. It can be noticed that the vitreous loss, in both the cases, were almost close by and further the cause for vitreous loss did depend more on the fragility and adherence properties of the anterior capsule, than on the technique chosen for doing capulotomy.

Mobility of the nucleus for proper trenching and phacoemulsifying of the lens was much better in Group2. This was because of the free anterior rim of the anterior capsule in Group2, which did not restrict the movement of the nucleus. In Group1, in some cases the movement of the nucleus was impeded by the presence of the continuous circular rim. In fact in all the cases of Group1 it was mandatory to use the second instrument through the side-port to expect a good nuclear mobility.

The corneal clarity at the end of the operation to $5^{\text {th }}$ postoperative weeks were in no way affected, by the method chosen for the anterior capsuloty, as the corneal clarity were $100 \%$ in both the groups.
In both the groups the reason for lens tilt astigmatism was due to the uneven support by the remnants of the anterior and posterior capsules, in cases of vitreous loss where in implantation of IOL were performed on the remnants of the anterior and posterior capsules.

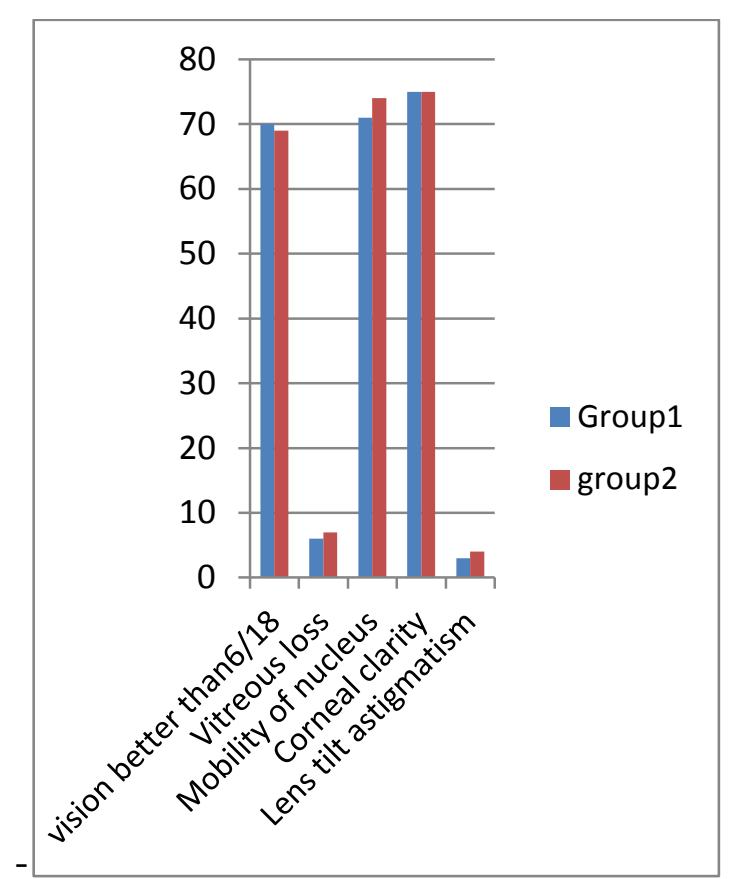

Figure $1 \mathrm{X}$ - axis parameters $\mathrm{Y}$-axis no. of patients

A note of importance here would be to mention that if accidentally long tags of anterior capsules are left behind accidentally in group2 variety of anterior capsulotomy, it can cause devastating results. So care was taken to excise these tags in 5 cases of canopener technique of anterior capsulotomy. Peroperatively these tags can cause extension of the capulotomy site to the equator during phacoemulsification. Post-operatively these tags can mechanically impede the vision, cause iridocapsular adhesions, cause capsular bag distortion due to adhesion to the remaining posterior capsule. All these phenomena can increase the incidence and number of cases going in for Nd-YAG laser capsulotomy and lens tilt astigmatism.

Continuous curvilinear capsulorhexis increases the resistance of capsular bag tear during phacoemulsification, when compared to anterior capsulotomy as mentioned in literature. In our study it can be noted, that there was no significant 
difference in the capsular bag tear, in both the groups during phacoemulsification. Hence before they can master CCC, anterior capsulotomy by canopener technique, can be safely advised for the post graduate students/beginners who intend to learn phacoemulsification with intraocular lens implantation. Care should always be taken in both the groups to confine to the central safe zone, while doing phacoemulsification. This helps in avoiding undue complications

The disadvantage of CCC is that, it can limit the movement of the nucleus in cases of cataracta brunescence, thereby causing difficulty in phacoemulsification In our study we found that in such situations anterior capsulotomy by Can-opener technique superseded the CCC. So in cases where there is hypermature cataract, and capsule is firmly adherent to the underlying cortex and nucleus, in such cases Can-opener technique can be used as a method of choice. Further the releasing incisions, that can be placed in Can-opener technique, offers the nucleus the freedom of movement which in turn both facilitates and accelerates the phacoemulsification procedure.

Studying the results of our study and considering the mean and standard deviation of various parameters considered we can note that, there are no marked differences between the various parameters, considered for the study, in both the groups selected in our study.

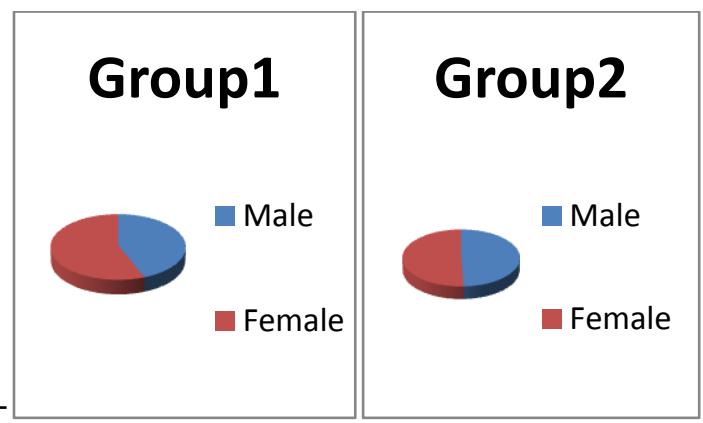

Figure 2 - Group1-Male-44\%. Female-56\%

Group2- Male-49.33\% Female-50.66\%

\section{Conclusion}

It is definitely true that respecting the aesthetics of the ocular surgery, it is important to emphasize and encourage one to do continuous curvilinear capsulorhexis, before phacoemulsification with intraocular lens implantation, nevertheless this study divulged the fact that even in cases of can-opener technique of anterior capsulotomy similar end result can definitely be obtained in phacoemulsification with intraocular lens implantation. This study thus concludes that, it is not mandatory or stringent to do Curvilinear Continuous Capsulorhexis before phacoemulsification with intraocular lens implantation. So the residents, postgraduate students, and the beginners who wish to learn phacoemulsification can certainly start Can-Opener technique of Anterior Capsulotomy, prior to mastering CCC.

\section{References}

1. Al-Attar L., Smiddy W.E., Schiffman J.C. Foldable versus rigid intraocular lenses in conjunction with pars plana vitrectomy and other vitreoretinal procedures. J Cataract Refract Surg. 2004;30(5):10921097. [PubMed]

2. Arshinoff S. Mechanics of capsulorhexis. $\mathbf{J}$ Cataract Refract Surg. 1992;18(6):623628.[PubMed]

3. Assia E.I., Apple D.J., Tsai J.C. The elastic properties of the lens capsule in capsularhexis .Am J Ophthalmol. 1991;111(5):628632. [PubMed]

4. Auffarth G.U., Reuland A.J., Heger T. Cataract surgery in eyes with iridoschisis using the Perfect Pupil iris extension system. J Cataract Refract Surg. 2005; 31(10):1877-1880.[PubMed]

5. Belovay G.W., Varma D.K., Ahmed I.I. Cataract surgery in pseudoexfoliation syndrome CurrOpin Ophthalmol. 2010;21(1):25-34. [PubMed]

6. Bohm P., Horvath J., Zahorcova M. Irrigating iris retractor for complicated cataract surgery. J Cataract Refract Surg. 2009;35(3):419-421. [PubMed]

7. Budning A., Rosen J. The elastic properties of the lens capsule in capsulorhexis. Am J 
Ophthalmol. 1991;112(4):474-

475. [PubMed]

8. Caporossi A., Balestrazzi A., Alegente M. Trypan blue staining of the anterior capsule: the one-drop technique. Ophthal Surg Lasers Imaging. 2005;36(5):432-434. [PubMed]

9. Chang D.F. Use of Malyugin pupil expansion device for intraoperative floppyiris syndrome: results in 30 consecutive cases. J Cataract Refract Surg. 2008;34(5):835-841.[PubMed]

10. Chang D.F., Braga-Mele R., Mamalis N. ASCRS White Paper: clinical review of intraoperative floppy-iris syndrome. $\mathrm{J}$ Cataract Refract Surg. 2008;34(12):21532162.[PubMed]

11. Comer R.M., Abdulla N., O'Keefe M. Radiofrequency diathermy capsulorhexis of the anterior and posterior capsules in pediatric cataract surgery: preliminary results. J Cataract Refract Surg. 1997;23(Suppl. 1):641-644. [PubMed]

12. Corey R.P., Olson R.J. Surgical outcomes of cataract extractions performed by residents using phacoemulsification. J Cataract Refract Surg. 1998;24(1):66-72. [PubMed]

13. Cruz O.A., Wallace G.W., Gay C.A. Visual results and complications of phacoemulsification with intraocular lens implantation performed by ophthalmology residents. Ophthalmology. 1992;99(3):448452. [PubMed]

14. Desai P., Minassian D.C., Reidy A. National cataract surgery survey 1997-8: a report of the results of the clinical outcomes. $\mathrm{Br} \mathrm{J}$ Ophthalmol. 1999;83(12):1336-1340.[PMC free article] [PubMed]

15. Dholakia S.A., Praveen M.R., Vasavada A.R. Completion rate of primary posterior continuous curvilinear capsulorhexis and vitreous disturbance during congenital cataract surgery. J

AAPOS. 2006;10(4):351-356. [PubMed]
16. Dick H.B., Krummenauer F., Augustin A.J. Healon5 viscoadaptive formulation: comparison to Healon and Healon GV. J Cataract Refract Surg. 2001;27(2):320326.[PubMed

17. Andreo L.K., Wilson M.E., Apple D.J. Elastic properties and scanning electron microscopic appearance of manual continuous curvilinear capsulorhexis and vitrectorhexis in an animal model of pediatric cataract. J Cataract Refract Surg. 1999;25(4):534-539. [PubMed]

18. Bartholomew L.R., Wilson M.E., Jr., Trivedi R.H. Pediatric anterior capsulotomy preferences of cataract surgeons worldwide: comparison of 1993, 2001, and 2003 surveys. J Cataract Refract Surg. 2007;33(5):893-900. [PubMed]

19. Buratto L. 2nd ed. SLACK Inc.; Thorofare, NJ: 2003. Phacoemulsification: principles and techniques.

20. Dada V.K., Sudan R., Sharma N. Trypan blue with a viscoelastic agent. J Cataract Refract Surg. 2002;28(2):205206. [PubMed] 